\title{
Definition, framework and research issues of smart learning environments - a context-aware ubiquitous learning perspective
}

\author{
Gwo-Jen Hwang
}

\author{
Correspondence: \\ gjhwang.academic@gmail.com \\ Graduate Institute of Digital \\ Learning and Education, National \\ Taiwan University of Science and \\ Technology, 43, Sec.4, Keelung Rd., \\ Taipei 106, Taiwan
}

\begin{abstract}
The rapid progress of mobile, wireless communication and sensing technologies has enabled the development of context-aware ubiquitous learning (u-learning) environments, which are able to detect the real-world learning status of students as well as the environmental contexts. Accordingly, appropriate information can be provided to individual students in the right place and at the right time. However, researchers have indicated that, to support students to learn in real-world contexts in smart ways, more factors need to be taken into account when designing and developing learning systems. In this paper, the definition and criteria of smart learning environments are presented from the perspective of context-aware ubiquitous learning. A framework is also presented to address the design and development considerations of smart learning environments to support both online and real-world learning activities. Moreover, some emerging technologies that might facilitate the development of smart learning environments as well as the features and criteria of smart learning are addressed. Finally, research issues related to smart learning are provided.
\end{abstract}

Keywords: Smart learning; Ubiquitous learning; Context awareness; Adaptive learning; Intelligent tutoring systems; Google glass; Augmented reality; Seamless learning

\section{Introduction}

Making learning systems smart has been the objective of many researchers in both the fields of computer science and education. Since the early 1980s, researchers have developed intelligent tutoring systems (ITSs) that incorporate artificial intelligence techniques in educational applications (Martens and Uhrmacher 2002; van Seters et al. 2012). As the aim of developing ITSs is to support individual students to learn by adapting the learning interfaces or materials based on their needs, ITSs are also called "adaptive learning systems" (Graf et al. 2010; Kinshuk and Lin 2003). Moreover, along with the popularity of computer networks and the World Wide Web, many learning systems have been implemented in the form of web-based learning systems (Karampiperis and Sampson 2005).

In the past decade, the rapid advancement of wireless communication networks and the popularity of mobile devices have enabled people to access digital resources and interact with computer systems without being limited by either location or time (Hwang and Chang 2011). Researchers call such a learning approach that utilizes 
mobile and wireless communication technologies "mobile learning" (Sharples et al. 2009). In the meantime, the presence of sensing technologies such as GPS (Global Positioning System), RFID (Radio-Frequency Identification) and QR (Quick Response) codes has further enabled learning systems to detect the real-world locations and contexts of learners. Hwang, Tsai and Yang (2008) call such a learning approach that employs mobile, wireless communication and sensing technologies to enable learners to interact with both the realworld and digital-world objects "context-aware ubiquitous learning". Many previous studies have reported the benefits of such an approach and have emphasized the importance of having students learn from the real world with access to digital resources (Bomsdorf 2005; Chu et al. 2010). That is, the focus of technology-enhanced learning has shifted from web-based learning to mobile learning and from mobile learning to context-aware ubiquitous learning, as indicated by Liu and Hwang (2010).

Although context-aware ubiquitous learning seems to provide a promising form of learning, it is still far from ideal technology-enhanced learning, which shall be called "smart learning" in this paper. A smart learning environment not only enables learners to access digital resources and interact with learning systems in any place and at any time, but also actively provides the necessary learning guidance, hints, supportive tools or learning suggestions to them in the right place, at the right time and in the right form. Basically, a smart learning system can be perceived as a technology-enhanced learning system that is capable of advising learners to learn in the real-world with access to the digital world resources. However, it is more than merely incorporating an intelligent tutoring system into a context-aware ubiquitous learning environment. There are several features that make such an innovative notion of learning go beyond the combination of the two. In the following sections, in-depth discussions are provided to clearly define "smart learning environment" and its framework; moreover, a comparison of smart learning environments, context-aware ubiquitous learning environments and intelligent tutoring systems is provided. Furthermore, relevant technologies and research issues of smart learning are presented to inspire those researchers and educators who are interested in developing and applying smart learning systems as well as investigating the relevant issues.

\section{Literature review}

In this section, several research topics related to the development of learning systems that can support students to learn in an efficient and effective way are reviewed. The intelligent tutoring and adaptive systems and context-aware ubiquitous learning systems are such systems that aim to provide personalized learning support based on students' preferences, learning status, personal factors as well as the characteristics of the learning contents and learning environments. On the other hand, Mindtools are computer programs that engage students in higher order and meaningful thinking during the learning process (Jonassen, Carr, and Yueh 1998). To help students comprehend and organize knowledge, solve problems and make inferences based on what they have learned, it is important to provide the right Mindtools for them to deal with different learning tasks or solve different types of problems at the right time and in the right context (Chu, Hwang, and Tsai 2010; Hwang, Hung, Chen, and Liu 2014); therefore, Mindtools also play an important role in helping students learn in smart ways. 


\section{Intelligent tutoring and adaptive learning}

An intelligent tutoring system or an adaptive learning system is developed for supporting students to probe and acquire knowledge based on their learning status and personal factors, such as learning progress, knowledge levels, learning styles, cognitive styles and preferences (Mampadi, Chen, Ghinea, and Chen 2011; Papanikolaou, Grigoriadou, Magoulas, and Kornilakis 2002; Yang et al. 2013a,b). A classical intelligent tutoring system usually consists of four components, that is, an expert model or expert knowledge model that contains the teaching materials, a student model or learner model that evaluates students' learning status and performance, an instructional model or pedagogical knowledge model that determines teaching content, educational tools and presentation methods based on the outcomes of the student model, and a user interface for interacting with students (Clancey 1984).

In the past decades, owing to the popularity of the World Wide Web, many researchers have attempted to develop adaptive learning systems on the web. Such web-based adaptive learning systems are known as adaptive educational hypermedia or adaptive hypermedia learning systems (Kinshuk et al. 2012; Specht et al. 1997).

Researchers have indicated that web-based systems, which present information as hypermedia, have the potential to provide personalized learning support or guidance to students based on their personal characteristics or learning performance (Chiou et al. 2010; Hwang 1998). In a hypermedia learning system, learning materials are associated with hyperlinks; therefore, it is possible to provide personalized presentation formats or learning paths by adapting the learning content or linking structure (Tseng et al. 2008a,b). Brusilovsky (2001) called the two adaptation strategies for providing personalized learning in web-based systems "adaptive presentation" and "adaptive navigation support". The former presents personalized learning materials while the latter guides individual students to browse learning content based on the recommended learning paths.

In the past decades, various adaptive hypermedia learning systems have been developed based on the two adaptation strategies; moreover, experiments have been conducted to show the effectiveness of the systems (Tseng et al. 2008a,b). For example, Gonzalez and Ingraham (1994) developed a hypermedia system that assigned exercises and provided supplementary materials to individual students based on their learning performance. Papanikolaou et al. (2002) demonstrated an adaptive learning system that adapted learning content based on individual students' knowledge levels. Karampiperis and Sampson (2005) employed an adaptive resource selection scheme to generate and select the best-fit learning paths for individual students. Martens (2005) further presented PLAIT (Planning Agents in Intelligent Tutoring), a web-based system that not only adapts web content based on learners' needs, but also employs case-based scenarios to evaluate their performance and provide context-dependent help by analyzing how they deal with the cases.

In addition to these attempts to employ different adaptation strategies, researchers have also tried to develop adaptive learning systems by taking different personal factors into account (Kinshuk et al. 2012). For example, Tseng et al. (2008a,b) developed a web-based learning system that adapted learning content and paths based on students' learning styles and knowledge levels evaluated based on a pre-test. Yang et al. (2013a,b) 
presented an adaptive learning system by taking both students' learning styles and cognitive styles into account.

Recently, owing to the advancement and popularity of mobile, wireless communication and sensing technologies, researchers have attempted to provide personalized learning guidance or support in real-world learning environments. For example, Hwang et al. (2010) developed an adaptive learning system to guide individuals to learn in a real-world environment based on the personalized learning paths generated by taking their learning status and the relationships between real-world learning targets into account; Hsieh et al. (2011) presented an adaptive learning system for guiding students to observe and learn in a butterfly garden based on their learning styles. It can be seen that applying intelligent tutoring or adaptive learning techniques to real-world learning scenarios has become an important and challenging issue of technology-enhanced learning.

\section{Context-aware ubiquitous learning}

The importance and necessity of situating students in real-world learning scenarios has been identified by educators for decades (Lave 1991; Hung et al. 2013). Without learning and practicing in authentic environments, students might find it difficult to apply the knowledge learned from the textbooks to solving practical problems (Brown et al. 1989). Therefore, many researchers have attempted to develop learning environments that combine real-world contexts and digital-world resources to provide students with direct experiences of the real world with sufficient learning support (Minami et al. 2004; Hung et al. 2014; Wu et al. 2013a,b). Context-aware ubiquitous learning is such an approach that enables students to learn from the real world with support from the learning system using mobile, wireless communication and sensing technologies (Hwang et al. 2008; Tsai et al. 2012).

In a context-aware ubiquitous learning environment, the learning system is able to detect the real-world status of learners using sensing technologies, interact with them via wireless networks, present learning guidance and offer supplementary materials or feedback to them via mobile devices. During the learning process, the learners' real-world learning status as well as the interactions between learners and the system can be recorded for further analysis. Various studies have demonstrated the benefits of context-aware ubiquitous learning in terms of helping students deal with problems as well as acquiring knowledge in the real world (Chu et al. 2010; Joiner et al. 2006; Rogers et al. 2005). For example, Ogata and Yano (2004) developed a context-aware ubiquitous learning system with GPS for guiding students to practice Japanese in the real world, while Hwang et al. (2012) developed a learning system with RFID for guiding students to operate scientific devices in a science park via assigning various "operating" tasks and evaluating their operating results.

In addition, several researchers have indicated the importance of providing effective learning strategies, tools and personalized learning support in context-aware ubiquitous learning activities (Hung et al. 2014; Wu et al. 2013a,b). That is, incorporating intelligent tutoring or adaptive learning techniques to context-aware ubiquitous learning has become one of the important issues of technology-enhanced learning. 


\section{Computer mindtools}

Mindtools are computer systems that engage students in meaningfully and constructively thinking and learning via stimulating or guiding them to interpret, analyze, synthesize and organize knowledge during the learning process (Chu et al. 2010). Jonassen et al. (1998) emphasized the importance of Mindtools by addressing that "technologies should not support learning by attempting to instruct the learners, but rather should be used as knowledge construction tools that students learn with, not from". Jonassen (1999) defined Mindtools as "a way of using a computer application program to engage learners in constructive, higher-order critical thinking about the subjects they are studying". He further indicated that several computer applications, such as database systems, spreadsheets, expert systems, semantic nets, video conferencing systems, multimedia and hypermedia authoring tools, programming tools and simulation programs, are potential Mindtools if they can be used in proper ways.

In the past decades, Mindtools have been widely used in research and school settings (Jonassen 2014; Nuutinen et al. 2010). For example, many school teachers have experience of using concept maps, a kind of semantic net, to help students organize what they have learned (Fischer et al. 2002; Hwang et al. 2011a,b; Novak and Musonda 1991; Peng et al. 2009). Recently, several researchers have reported the effectiveness of applying Mindtools to real-world learning activities using mobile devices (Hwang et al. 2014; Yang et al. 2013a,b). For example, Hwang et al. (2011a,b) developed a concept map-based ubiquitous learning environment for conducing in-field activities in a butterfly garden. It can be predicted that Mindtools have the potential to help students cope with complicated knowledge, in particular, when they need to face complex learning scenarios that combine rich information from both the real and the virtual worlds.

\section{Definition, criteria and framework of a smart learning environment}

From the aspect of context-aware ubiquitous learning, contexts include the interactions between learners and environments; therefore, "smart learning environments" can be regarded as the technology-supported learning environments that make adaptations and provide appropriate support (e.g., guidance, feedback, hints or tools) in the right places and at the right time based on individual learners' needs, which might be determined via analyzing their learning behaviors, performance and the online and realworld contexts in which they are situated (Hwang et al. 2008). It should be noted that learning in a smart learning environment does not imply that students have only a limited amount of leisure time; that is, no particular learning schedule is used to replace their leisure activities. A smart learning environment aims to help students gain knowledge even when they are doing leisure activities. It plays the role of a wise friend who seeks opportunities to advise learners in their daily life by taking their needs and preferences into account.

Accordingly, the potential criteria of a smart learning environment are summarized as follows:

(1) A smart learning environment is context-aware; that is, the learner's situation or the contexts of the real-world environment in which the learner is located are 
sensed, implying that the system is able to provide learning support based on the learner's online and real-world status.

(2) A smart learning environment is able to offer instant and adaptive support to learners by immediate analyses of the needs of individual learners from different perspectives (e.g., learning performance, learning behaviors, profiles, personal factors) as well as the online and real-world contexts in which they are situated. Moreover, it can actively provide various personalized support to the learners, including learning guidance, feedback, hints and learning tools, based on their needs.

(3) A smart learning environment is able to adapt the user interface (i.e., the ways of presenting information) and the subject contents to meet the personal factors (e.g., learning styles and preferences) and learning status (e.g., learning performance) of individual learners. The user interface is not necessarily a conventional computer. Instead, learners can interact with the learning environment via mobile devices (e.g., smartphones or tablet computers), wearable devices (e.g., Google Glass or a digital wristwatch), or even ubiquitous computing systems embedded in everyday objects. Therefore, it is a challenging issue to adapt the user interface to meet the learners' needs in a smart learning environment.

It should be noted that the smart learning environment is defined to be minimally context-aware (i.e., only the online and real-world states of learners are considered as the context of learning), minimally adaptive (i.e., the adaptivity with respect to emotional states, cognitive capacity, motivation, and socio-economic factors are not considered), and minimally personalized (i.e., pedagogy-oriented guidance is not considered). Therefore, it only represents the essential criteria for researchers and system developers to implement smart learning environments. As shown in Figure 1, the framework of a smart learning environment basically consists of the following modules:

(1) A learning status detecting module. This module detects learners' real-world status (e.g., locations and learning behaviors) and environmental contexts (e.g., temperature and humidity) via connecting to some sensing devices.

(2) A learning performance evaluation module. This module evaluates and records learners' performance by conducting tests online or in the real world. For a real-world test, the learners might be asked to find the answer to a test item via observing or interacting with real-world targets (i.e., the real-world objects related to the learning goals, such as a plant on school campus).

(3) An adaptive learning task module. This module assigns learning tasks to learners based on their learning progress, learning performance, personal factors and their learning objectives in all disciplines. The learning task could be an online inquiry task that engages learners in searching for information on the Web, or a real-world inquiry task that requires the learners to observe real-world targets, raise questions, search for supplementary materials from the Internet or in the real-world 


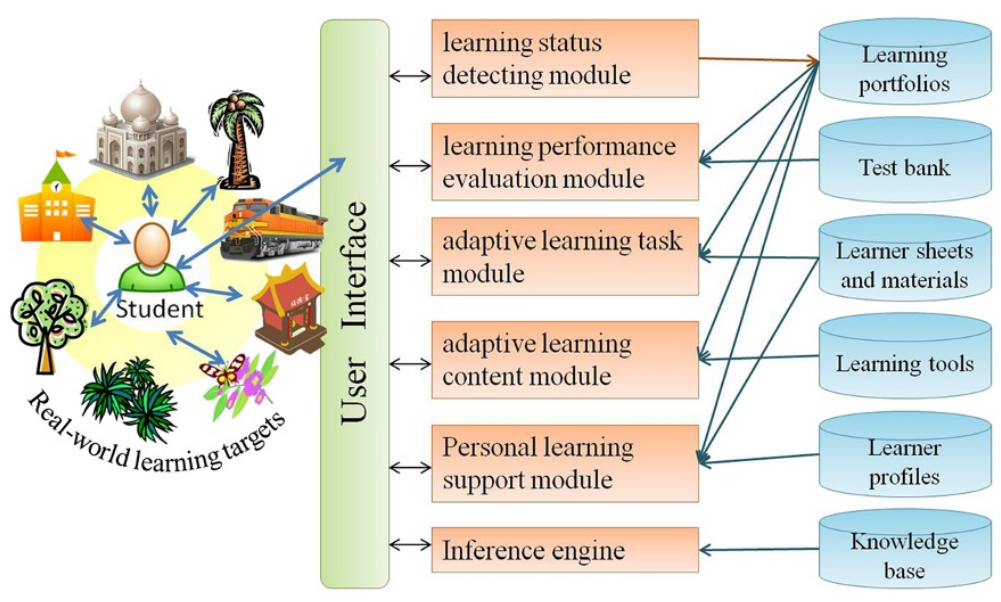

Wireless communication network

Figure 1 Framework of a smart learning environment.

environment, propose hypotheses and present answers to the questions. With the help of this module, the learners are always engaged in the most feasible and important learning tasks by considering their learning status and personal factors in the right place and at the right time.

(4) An adaptive learning content module. This module provides learning materials to learners. Based on the learning progress, learning performance, personal factors and the real-world status of individual learners, the learning system recommends and organizes learning materials, and adapts the user interface to meet individual learners' needs.

(5) A personal learning support module. This module provides learning support to learners based on their learning needs. The learning support can be a guideline of the learning task or learning content, a hint for the learning task, feedback on their work, or a Mindtool to help them learn in an efficient and effective way. To determine what kind of support is to be provided, the features of the learning tasks and learning content as well as the learning performance, personal factors and real-world status of the learners need to be taken into consideration.

(6) A set of databases for keeping the learner profiles, learning portfolios, learning sheets (i.e., the sheets that present the learning tasks for each subject unit or learning topic), learning materials, test items and learning tools. The data in those databases are very helpful to the learning system in terms of providing suitable support to the students in the right place and at the right time. For example, in the learning portfolio database are kept the students' learning schedules, learning progress, homework, assessment results and their interactions with peers and the learning system. Via analyzing the records in the learning portfolios, the learning system knows individual students' to-be-enhanced concepts or skills, and hence the most suitable learning tasks can be assigned to them along with some recommended strategies or tools on the right occasion.

(7) An inference engine and a knowledge base for determining the "value" of the candidate learning tasks, strategies and tools as well as their possible combinations. The knowledge base is a collection of the tutoring knowledge and experience of 
educators and teachers. It might also contain the decision-making rules generated by analyzing previous cases, including those successful and unsuccessful ones. The inference engine is a computer program that makes decisions by analyzing the current case (i.e., the status of the student and the environmental contexts) based on the rules in the knowledge base (Wu et al. 2013a,b).

Based on those criteria and the framework, a comparison of a smart learning environment, a context-aware u-learning environment and a conventional adaptive learning environment is presented in Table 1. It can be seen that a smart learning environment is more than a combination of context-aware u-learning and adaptive learning. In particular, it guides learners to do the right thing (i.e., the tasks that are most feasible and important to the learner at present) in the right way (i.e., with effective learning tools or strategies) at the right time and in the right place based on individual learners' online and real-world learning status as well as their personal factors.

Consider a learner, say John, is going home after school. When John passes through a garden, the learning system identifies that one of the trees is related to what he has learned in school in his natural science course. Moreover, John has mentioned that he would like to see the real trees if possible. As there is still plenty of time for John to get home for dinner, the learning system reminds him to note the tree and provides him with some relevant learning materials. In addition, the learning system recommends that he do a learning task, that is, to complete a concept map about the ecology of the target tree based on his observations of the tree as well as what he has learned from

Table 1 Comparisons of smart learning, context-aware u-learning systems and adaptive learning

\begin{tabular}{|c|c|c|c|}
\hline & $\begin{array}{l}\text { Smart } \\
\text { learning }\end{array}$ & $\begin{array}{l}\text { Context-aware } \\
\text { u-learning }\end{array}$ & $\begin{array}{l}\text { Adaptive } \\
\text { learning }\end{array}$ \\
\hline Detects and takes into account the real-world contexts & Yes & Yes & No \\
\hline Situates learners in real-world scenarios & Yes & Yes & No \\
\hline Adapts learning content for individual learners & Yes & No & Yes \\
\hline Adapts the learning interface for individual learners & Yes & No & Yes \\
\hline Adapts learning tasks or objectives for individual learners & Yes & No & No \\
\hline Provides personalized feedback or guidance & Yes & Yes & Yes \\
\hline Provides learning guidance or support across disciplines & Yes & No & No \\
\hline $\begin{array}{l}\text { Provides learning guidance or support across contexts (e.g., in } \\
\text { classrooms, on school campuses, in the library, and on the street) }\end{array}$ & Yes & Yes & No \\
\hline Recommends learning tools or strategies & Yes & No & No \\
\hline Considers the online learning status of learners & Yes & No & Yes \\
\hline Considers the real-world learning status of learners & Yes & Yes & No \\
\hline Facilitates both formal and informal learning & Yes & Yes & No \\
\hline $\begin{array}{l}\text { Takes multiple personal factors and environmental factors (e.g., learning } \\
\text { needs, preferences, schedules and real-world contexts) into account }\end{array}$ & Yes & No & No \\
\hline $\begin{array}{l}\text { Interacts with users via multiple channels (e.g., smartphones, } \\
\text { Google Glass, or other ubiquitous computing devices) }\end{array}$ & Yes & Yes & No \\
\hline $\begin{array}{l}\text { Provides support to learners with "in advance adaptation" across } \\
\text { real and virtual contexts }\end{array}$ & Yes & No & No \\
\hline $\begin{array}{l}\text { Provides support to learners with "on the run adaptation" across } \\
\text { real and virtual contexts }\end{array}$ & Yes & No & No \\
\hline
\end{tabular}


the textbook. Consider another learner, Mary, who is a new foreign student in the United States. When she is walking home after school, the learning system detects a nearby convenience store. As Mary failed to answer several questions related to the merchandise in convenience stores earlier in her English class, the learning system tries to situate her in the real-world scenario to help her memorize the English terms; therefore, it guides her to the convenience store and finds the location of those items. Following that, some learning tasks are conducted to practice some relevant English terms; for example, the learning system might give some frequently used sentences in the convenience store and encourage her to interact with the worker to practice her English.

It should be noted that a conventional context-aware ubiquitous learning system does not guide students to learn unless the real-world targets (e.g., the trees, convenience store, merchandise and worker) are related to the learning objectives defined by the teachers or the learning needs of the students. That is, most mobile or ubiquitous learning systems mainly provide learning guidance or other forms of support to students in formal school settings. For informal learning, those systems usually provide supplementary materials in a passive manner. On the contrary, a smart learning environment can always seamlessly provide the most needed tasks or support to learners by taking multiple personal factors (e.g., preferences, learning needs, personal schedule) and environmental factors (e.g., location of the real-world target) into account without being limited by any particular domain, no matter whether they are in school or not. More importantly, the support provided to learners is not only learning guidance or supplementary materials, but also some appropriate learning strategies or tools.

\section{Technologies facilitating smart learning}

The rapid advancement of computer and communication technologies is speeding up the development of smart learning environments. In the past decade, the popularity of mobile devices (e.g., smart phones and tablet computers), wireless communication networks and sensing technologies (e.g., RFID, GPS and QR codes) have fulfilled the basic requirements of developing smart learning environments. Via using those technologies, the learning systems are able to detect and collect real-world learning contexts of learners as well as their interactions with the online learning environment. However, for a smart learning environment, these currently popular technologies might not be good enough (Sherman and Craig 2003). For example, it could be dangerous for students to learn with smartphones or tablet computers while they are walking on the street, although there might be real-world targets related to some important learning objectives around them (Wu et al. 2013a,b). Moreover, it could be difficult for students to read the corresponding instructions from mobile devices when observing real-world targets. The drawbacks of some popular sensing technologies could also be a barrier to developing a smart learning environment. For example, reading QR codes or passive RFID tags requires the cooperation of the learners. Before the learners scan the correct codes or tags, the learning system can do nothing but wait. In addition, for most realworld targets in our daily life, there are no codes or tags; in that case, it is not possible for the learning system to actively remind the learners to note the targets that might be worth studying. 
The advancement and growing popularity of Augmented Reality (AR), computer vision and speech recognition technologies further provide new opportunities to make the learning environments even smarter.

AR is a technology that allows learners to see real-world and digital-world information in an integrated mode (Dunleavy et al. 2009). Although currently AR and mobile technologies seem to share the same hardware (e.g., smartphones and tablet computers), the benefits of AR are much more than the provision of "portability" and "accessibility" of learning resources; rather, AR provides a way to precisely incorporate necessary and important supplementary information (e.g., digital data or virtual objects) into a realtime view of real-world targets; moreover, it enables real-time interaction between the real and virtual objects (Azuma et al. 2001; Kye and Kim 2008; Wu et al. 2013a,b). Such an integrated real and virtual presentation and interaction technology has been highly recommended by researchers as being a potential approach to developing more powerful and supportive learning environments (Andujar et al. 2011; Kamarainen et al. 2013).

Computer vision refers to the technology of acquiring and analyzing images in order to understand the image contents, such as numerical and symbolic information, or objects in the images (Hartley and Zisserman 2003). With the help of the computer vision technology, the learning systems are able to recognize the real-world objects surrounding the learners and actively provide learning support to them if necessary. On the other hand, the speech recognition technology enables learners to conveniently and efficiently interact with learning systems, such as giving commands for accessing information or browsing web pages, or inputting data for answering questions or communicating with peers (Jelinek 1997).

The presence of Google Glass further provides a great opportunity to apply AR, computer vision and speech technologies to the development of ideal smart learning environments (Albanesius 2012). Google Glass is a wearable computer with an optical head-mounted display. It enables users to access digital resources and interact with real-world objects ubiquitously without the burden of carrying an additional device in the hand. More importantly, it allows users to communicate with application programs via natural language voice commands. It can be foreseen that Google Glass will become the major device for supporting smart learning from the perspective of anytime and anywhere learning.

In addition, many other mobility-unrelated technologies can also support the development of smart learning environments. For example, Analytics technologies could combine a student's personal aspirations in assessing the value of a prescribed learning opportunity (Simpao et al. 2014; Tannahill and Jamshidi 2014). Social-awareness technologies could relate an individual's experience with that of the crowd in establishing groups (Bardram and Hansen 2010).

\section{Research issues of smart learning}

As mentioned in the above sections, smart learning is a new concept of technologyenhanced learning. It is more than integrating the criteria and functions of intelligent tutoring systems and context-aware ubiquitous learning systems; therefore, the following research issues are raised to acknowledge the presence of the "smart learning" conception: 
(1) Development of implementation frameworks of smart learning environments: The rapid advancement of digital technologies (e.g., AR, computer vision, speech recognition, mobile and wearable technologies) and analytics technologies (e.g., learning analytics and social-awareness technologies) provides various possibilities of implementing smart learning environments based on different educational purposes and from different perspectives of pedagogical theories. Therefore, it is an important and challenging issue to propose implementation frameworks of smart learning environments with these emerging technologies.

(2) Interpretations and examination of existing pedagogical theories for smart learning environments: New learning modes will raise new pedagogic issues, and smart learning is a brand new concept of learning; therefore, researchers or educators may propose new thoughts about its pedagogy based on those existing theories, such as constructivism, motivational theory, the technology acceptance model, cognitive load theory and multimedia design theory (Brown et al. 1989; Mayer 2001; Mayer and Moreno 2003).

(3) Learning and assessment strategies for smart learning: In such a new educational mode as smart learning, the existing technology-enhanced learning and assessment strategies might need to be reconsidered and revised. Moreover, new learning concepts might provide good opportunities for researchers to develop new strategies for helping learners more effectively and efficiently gain knowledge and solve problems in the real world.

(4) Innovative applications of learning and training in the new learning mode: From some review papers, it is found that technologies have seldom been applied to some courses or domains, such as arts, design and physical education courses (Hsu et al. 2012; Hwang and Tsai 2011). It is expected that with new technologies and new learning concepts, researchers will be able to explore new application domains that are difficult to implement in the existing learning environments.

(5) Learning performance and perception evaluation: Knowing more about the learning performances and perceptions of learners is very useful for researchers to develop more effective smart learning environments. The evaluation can be conducted from various aspects, such as learning achievement, problem-solving ability, technology acceptance degree, learning motivation, learning attitude, self-efficacy and self-regularity. In the meantime, it is worth investigating the effects of smart learning environments on the learning performance and perceptions of students with different learning styles, cognitive styles, or other personal characteristics.

(6) Learning behavior and learning pattern analysis: Having an in-depth understanding of learners' behaviors and learning patterns in the integrated real-world and virtual-world environments is helpful to researchers and educators in developing more effective learning tools and strategies. As a smart learning environment is capable of recording every detail of the students' learning behaviors, it provides a good opportunity for researchers to acquire valuable and detailed information via analyzing these behaviors. More importantly, long-term observations and analysis of learning behaviors could be 
conducted such that researchers are able to know more about the social impacts of the new educational technology.

\section{Conclusions}

The presence and advancement of new computer, communication and sensing technologies have offered great and exciting opportunities to develop new learning environments. Smart learning is such a new concept for developing more powerful and helpful learning environments than existing technology-enhanced learning approaches by incorporating new technologies and new criteria for learning.

In the near future, it can be foreseen that the development and evaluation of smart learning systems with new mobile and sensing technologies will be the main focus for researchers from the fields of computer science and educational technology. In the meantime, it is important to promote the ideas of smart learning as well as the potential benefits of using those new technologies to school teachers. A smart learning environment cannot be complete without the cooperation of educational researchers, computer science researchers and school teachers, who play the roles of developing learning support, implementing learning functions and providing learning contents/objectives, respectively.

It can be predicted that the proposition of new learning concepts might raise several disputed issues, such as the ethics and moral principles of applying technologies in education, which are no doubt necessary topics for discussion. On the other hand, it is worth noting the potential positive effects of smart learning, including the provision of more effective and efficient learning support, the capability of better knowing the learning behaviors of learners, and the chance of conducting long-term and seamless learning activities. Therefore, it is concluded that the coming of smart learning environments is not only expected but also exciting.

Competing interests

The authors declare that they have no competing interests.

\section{Acknowledgements}

This study is supported in part by the National Science Council of Taiwan under contract numbers NSC 101-2511-S-011-005-MY3 and NSC 102-2511-S-011-007-MY3. The author would like to thank Ms. Li-Yu, Chiu for her assistance in refining part of the content of this paper.

Received: 20 May 2014 Accepted: 3 September 2014

Published online: 07 November 2014

References

C Albanesius, Google'project glass' replaces the smartphone with glasses. PC Mag. 4, (2012)

JM Andujar, A Mejias, MA Marquez, Augmented reality for the improvement of remote laboratories: an augmented remote laboratory. IEEE Trans. Educ. 54(3), 492-500 (2011)

R Azuma, Y Baillot, R Behringer, S Feiner, S Julier, B Maclntyre, Recent advances in augmented reality. IEEE Comput. Graph. Appl. 21(6), 34-47 (2001)

JE Bardram, TR Hansen, Context-based workplace awareness concepts and technologies for supporting distributed awareness in a hospital environment. Comput Supported Cooperative Work J Collaborative Comput 19(2), 105-138 (2010)

B Bomsdorf, Adaptation Of Learning Spaces: Supporting Ubiquitous Learning In Higher Distance Education. Paper Presented At The Meeting Of Mobile Computing And Ambient Intelligence: The Challenge Of Multimedia, Dagstuhl Seminar Proceedings 05181 (Schloss Dagstuhl, Germany, 2005). Retrieved on August 7, 2008 from http://drops.dagstuhl.de/opus/volltexte/2005/371/pdf/05181.BomsdorfBirgit.Paper.371.pdf

JS Brown, A Collins, P Duguid, Situated cognition and the culture of learning. Educ. Res. 18(1), 32-42 (1989)

P Brusilovsky, Adaptive hypermedia. User Model User Adapt Interact 11, 87-110 (2001)

CK Chiou, Tseng, CR Judy, GJ Hwang, S Heller, An adaptive navigation support system for conducting context-aware ubiquitous learning in museums. Comput. Educ. 55(2), 834-845 (2010)

HC Chu, GJ Hwang, CC Tsai, A knowledge engineering approach to developing mindtools for context-aware ubiquitous learning. Comput. Educ. 54(1), 289-297 (2010)

WJ Clancey, Methodology For Building An Intelligent Tutoring System, in Methods And Tactics In Cognitive Science, ed. by W Kintsch, PG Polson, JR Miller (Lawrence Erlbaum Associates, Hillsdale, NJ, 1984), pp. 51-84 
M Dunleavy, C Dede, R Mitchell, Affordances and limitations of immersive participatory augmented reality simulations for teaching and learning. J. Sci. Educ. Technol. 18(1), 7-22 (2009)

F Fischer, J Bruhn, C Grasel, H Mandl, Fostering collaborative knowledge construction with visualization tools. Learn. Instr. 12, 213-232 (2002)

AV Gonzalez, LR Ingraham, Automated exercise progression in simulation-based training. IEEE Transactions on System, Man, Cybernetics 24(6), 863-874 (1994)

S Graf, Kinshuk, C Ives, A Flexible Mechanism For Providing Adaptivity Based On Learning Styles In Learning Management Systems, in Proceedings of the IEEE International Conference on Advanced Learning Technologies (ICALT 2010) (IEEE Computer Society, Los Alamitos, CA, 2010), pp. 30-34

R Hartley, A Zisserman, Multiple view geometry in computer vision (Cambridge University Press, London, England, 2003)

SW Hsieh, YR Jang, GJ Hwang, NS Chen, Effects of teaching and learning styles on students' reflection levels for ubiquitous learning. Comput. Educ. 57(1), 1194-1201 (2011)

YC Hsu, SN Ho, CC Tsai, GJ Hwang, HC Chu, CY Wang, Research Trends in Technology-based Learning from 2000 to 2009: a content analysis of publications in selected journals. Educ Technol Soc 15(2), 354-370 (2012)

PH Hung, GJ Hwang, YF Lin, TH Wu, IH Su, Seamless connection between learning and assessment- applying progressive learning tasks in mobile ecology inquiry. Educ Tech Soc 16(1), 194-205 (2013)

IC Hung, XJ Yang, WC Fang, GJ Hwang, NS Chen, A context-aware video prompt approach to improving in-field reflection levels of students. Comput. Educ. 70(1), 80-91 (2014)

GJ Hwang, A tutoring strategy supporting system for distance learning on computer networks. IEEE Trans. Educ. 41(4), 1-19 (1998)

GJ Hwang, HF Chang, A formative assessment-based mobile learning approach to improving the learning attitudes and achievements of students. Comput. Educ. 56(4), 1023-1031 (2011)

GJ Hwang, CC Tsai, Research trends in mobile and ubiquitous learning: a review of publications in selected journals from 2001 to 2010. Br. J. Educ. Technol. 42(4), E65-E70 (2011)

GJ Hwang, CC Tsai, SJH Yang, Criteria, strategies and research issues of context-aware ubiquitous learning. Educ. Technol. Society 11(2), 81-91 (2008)

GJ Hwang, FR Kuo, PY Yin, KH Chuang, A heuristic algorithm for planning personalized learning paths for context-aware ubiquitous learning. Comput. Educ. 54(2), 404-415 (2010)

GJ Hwang, YR Shi, HC Chu, A concept map approach to developing collaborative Mindtools for context-aware ubiquitous learning. Br. J. Educ. Technol. 42(5), 778-789 (2011a)

GJ Hwang, PH Wu, HR Ke, An interactive concept map approach to supporting mobile learning activities for natural science courses. Comput. Educ. 57(4), 2272-2280 (2011b)

GJ Hwang, CC Tsai, HC Chu, Kinshuk, CY Chen, A context-aware ubiquitous learning approach to conducting scientific inquiry activities in a science park. Australas. J. Educ. Technol. 28(5), 931-947 (2012)

GJ Hwang, PH Hung, NS Chen, GZ Liu, Mindtool-Assisted In-Field Learning (MAIL): An advanced ubiquitous learning project in Taiwan. Educ. Technol. Soc 17(2), 4-16 (2014)

F Jelinek, Statistical methods for speech recognition (MIT Press, London, England, 1997)

R Joiner, J Nethercott, R Hull, J Reid, Designing educational experiences using ubiquitous technology. Comput. Hum. Behav. 22(1), 67-76 (2006)

DH Jonassen, Computers As Mindtools For Schools, Engaging Critical Thinking (Prentice-Hall, Englewood Cliffs, NJ, 1999)

DH Jonassen, Mindtools (Productivity and Learning). Encyclopedia. Sci. Educ, 1-7 (2014)

DH Jonassen, C Carr, HP Yueh, Computers as Mindtools for engaging learners in critical thinking. TechTrends 43(2), 24-32 (1998)

AM Kamarainen, S Metcalf, T Grotzer, A Browne, D Mazzuca, MS Tutwiler, C Dede, EcoMOBILE: Integrating augmented reality and probeware with environmental education field trips. Comput. Educ. 68, 545-556 (2013)

P Karampiperis, D Sampson, Adaptive learning resources sequencing in educational hypermedia systems. Educ. Technol. Soc 8(4), 128-147 (2005)

Kinshuk, T Lin, User exploration based adaptation in adaptive learning systems. Int. J. Inf. Syst. Educ 1(1), 22-31 (2003)

Kinshuk, NS Chen, S Graf, GJ Hwang, Adaptive Learning Systems, in Knowledge Management, Organizational Intelligence and Learning and Complexity, ed. by UNESCO-EOLSS Joint Commitee (Encyclopedia of Life Support Systems(EOLSS), Developed under the Auspices of the UNESCO, Eolss Publishers, Oxford,UK, 2012). Retrieved from http://www.eolss. net (Retrieved February 1, 2013)

B Kye, Y Kim, Investigation of the relationships between media characteristics, presence, flow, and learning effects in augmented reality based learning augmented reality. Int. J. Educ. Media. Technol 2(1), 4-14 (2008)

$J$ Lave, Situating learning in communities of practice. Perspect. Socially. Shared. Cogn 2, 63-82 (1991)

GZ Liu, GJ Hwang, A key step to understanding paradigm shifts in e-learning: Towards context-aware ubiquitous learning. Br. J. Educ. Technol. 41(2), E1-E9 (2010)

F Mampadi, SYH Chen, G Ghinea, MP Chen, Design of adaptive hypermedia learning systems: a cognitive style approach. Comput. Educ. 56(4), 1003-1011 (2011)

A Martens, Modeling Of Adaptive Tutoring Processes, in Web-Based Intelligent e-Learning Systems: Technologies and Applications, ed. by ZM Ma, Chapter 10th edn. (Information Science Publishing, Hershey, London, 2005), pp. 193-215

A Martens, AM Uhrmacher, Adaptive Tutor Processes and Mental Plans. Lect. Notes Comput. Sci 2363, 71-80 (2002)

RE Mayer, Multimedia Learning (Cambridge University Press, New York, 2001)

RE Mayer, R Moreno, Nine ways to reduce cognitive load in multimedia learning. Educ. Psychol. 38(1), 43-52 (2003)

M Minami, H Morikawa, T Aoyama, The Design Of Naming-Based Service Composition System For Ubiquitous Computing Applications, in In the Proceedings of the 2004 International Symposium on Applications and the Internet Workshops (SAINTW'04) (IEEE Computer Society, Washington, DC, 2004), pp. 304-312

JD Novak, D Musonda, A twelve-year longitudinal study of science concept learning. Am. Educ. Res. J. 28, 117-153 (1991)

J Nuutinen, E Sutinen, A Botha, P Kommers, From Mindtools to social Mindtools: Collaborative writing with Woven Stories. Br. J. Educ. Technol. 41(5), 753-775 (2010) 
H Ogata, Y Yano, Context-Aware Support For Computer-Supported Ubiquitous Learning, in Paper presented at the 2nd IEEE International Workshop on Wireless and Mobile Technologies in Education (JhongLi, Taiwan, 2004). Retrieved on September 6, 2014 from http://citeseerx.ist.psu.edu/viewdoc/summary:jsessionid=1D4E1240C9BCF5820DA7B01377E526C9?doi=10.1.1.81.5480

KA Papanikolaou, M Grigoriadou, GD Magoulas, H Kornilakis, Towards new forms of knowledge communication: the adaptive dimension of a web-based learning environment. Comput. Educ. 39, 333-360 (2002)

HY Peng, YJ Su, C Chou, CC Tsai, Ubiquitous knowledge construction: mobile learning re-defined and a conceptual framework. Innov. Educ. Teach. Int 46(2), 171-183 (2009)

Y Rogers, S Price, C Randell, DS Fraser, M Weal, G Fitzpatrick, Ubi-learning integrating indoor and outdoor learning experiences. Communications of the ACM 48(1), 55-59 (2005)

M Sharples, M Milrad, I Arnedillo Sánchez, G Vavoula, Mobile Learning: Small devices, Big Issues, in Technology Enhanced Learning: Principles and Products, ed. by N Balacheff, S Ludvigsen, T de Jong, A Lazonder, S Barnes (Springer, Heidelberg, 2009), pp. 233-240

WR Sherman, AB Craig, Understanding Virtual Reality (Morgan Kaufmann Publishers, New York, 2003)

AF Simpao, LM Ahumada, JA Gálvez, MA Rehman, A review of analytics and clinical informatics in health care. J. Med. Syst. 38(4), 1-7 (2014)

M Specht, G Weber, S Heitmeyer, V Schöch, AST: Adaptive WWW-Courseware for Statistics, in Proceedings of Workshop "Adaptive Systems and User Modeling on the World Wide Web" at $6^{\text {th }}$ International Conference on User Modeling, June 2-5, 1997, Chia Laguna, Sardinia, ed. by P Brusilovsky, J Fink, J Kay (Italy, 1997), pp. 91-95. http://www.contrib.andrew. cmu.edu/ plb/UM97_workshop/Specht.html

BK Tannahill, M Jamshidi, System of systems and big data analytics- bridging the gap. Comput. Electrical. Eng. 40(1), 2-15 (2014)

PS Tsai, CC Tsai, GJ Hwang, Developing a survey for assessing preferences in constructivist context-aware ubiquitous learning environments. J. Comp. Assist. Learn. 28(3), 250-264 (2012)

JCR Tseng, HC Chu, GJ Hwang, CC Tsai, Development of an adaptive learning system with two sources of personalization information. Comput. Educ. 51(2), 776-786 (2008a)

SS Tseng, JM Su, GJ Hwang, GH Hwang, CC Tsai, CJ Tsai, An object-oriented course framework for developing adaptive learning systems. Educ. Technol. Soc. 11(2), 171-191 (2008b)

JR van Seters, MA Ossevoort, J Tramper, MJ Goedhart, The influence of student characteristics on the use of adaptive e-learning material. Comput. Educ. 58, 942-952 (2012)

HK Wu, SWY Lee, HY Chang, JC Liang, Current status, opportunities and challenges of augmented reality in education. Comput. Educ. 62, 41-49 (2013a)

PH Wu, GJ Hwang, WH Chai, An expert system-based context-aware ubiquitous learning approach for conducting science learning activities. Educ. Technol. Soc. 16(4), 217-230 (2013b)

CC Yang, CM Hung, GJ Hwang, SS Tseng, An evaluation of the learning effectiveness of concept map-based science book reading via mobile devices. Educ. Technol. Soc 16(3), 167-178 (2013a)

TC Yang, GJ Hwang, SJH Yang, Development of an adaptive learning system with multiple perspectives based on students' learning styles and cognitive styles. Educ. Technol. Soc. 16(4), 185-200 (2013b)

doi:10.1186/s40561-014-0004-5

Cite this article as: Hwang: Definition, framework and research issues of smart learning environments - a

context-aware ubiquitous learning perspective. Smart Learning Environments 2014 1:4.

\section{Submit your manuscript to a SpringerOpen ${ }^{\circ}$ journal and benefit from:}

- Convenient online submission

- Rigorous peer review

- Immediate publication on acceptance

- Open access: articles freely available online

- High visibility within the field

Retaining the copyright to your article

Submit your next manuscript at $\boldsymbol{\nabla}$ springeropen.com 